\title{
The Influence of Pronated Foot Posture on Knee Isokinetic Strength, Static and Dynamic Postural Stability in Healthy Young Individuals
}

\author{
Woochan Chun ${ }^{1}$, Hee-su Kim¹, Sieun Park², PT, PhD, Jihea Park' ${ }^{1}$, Seunghee Shim¹, Sookyoung Park ${ }^{1}$, PT, PhD \\ ${ }^{1}$ Department of Physical Therapy, College of Health and Welfare, Woosong University, Daejeon, ${ }^{2}$ Department of Physical Therapy, Taegu \\ Science University, Daegu, Korea
}

\author{
Article Info \\ Received July 13, 2021 \\ Revised July 22, 2021 \\ Accepted July 22, 2021 \\ Corresponding Author \\ Sookyoung Park \\ E-mail: likeit20@wsu.ac.kr \\ https://orcid.org/0000-0001-6891-8844
}

\section{Key Words}

Foot posture

Muscle strength

Postural balance

Pronated foot
Background: The foot is a complex body structure that plays an important role in static and dynamic situations. Previous studies have reported that altered foot posture might affect knee joint strength and postural stability, however their relationship still remains unclear.

Objects: The purpose of this study was to identify whether pronated foot posture has an influence on knee isokinetic strength and static and dynamic postural stability.

Methods: Forty healthy young males aged 18 to 26 years were included. Foot posture was evaluated using the Foot Posture Index-6 (FPI-6), and the subjects were divided into two groups according to their FPI- 6 scores: a neutral foot group ( $n=20$, FPI- 6 score 0 to +5 ) and a pronated foot group ( $n=20$, FPI- 6 score +6 or more). Biodex Systems 3 isokinetic dynamometer was used to evaluate knee isokinetic strength and hamstring to quadriceps ratio at three angular velocities: $60 \% \mathrm{sec}, 90 \% \mathrm{sec}$, and $180 \% \mathrm{sec}$. The static and dynamic postural stability in a single-leg stance under the eyes-open and eyes-closed conditions were measured with a Biodex Balance System.

Results: There were no significant differences between the groups in knee isokinetic strength and static postural stability $(p>0.05)$, but there was a significant difference in the mediallateral stability index (MLSI) for dynamic postural stability under the eyes-closed condition ( $p$ $=0.022$ ). The FPI- 6 scores correlated significantly only with the dynamic overall stability index $(\mathrm{OSI})$ and the MLSI (OSI: $\mathrm{R}=0.344, \mathrm{p}=0.030 ; \mathrm{MLSI}: \mathrm{R}=0.409, \mathrm{p}=0.009)$ under the eyesclosed condition.

Conclusion: Participants with pronated foot had poorer medial-lateral dynamic stability under an eyes-closed condition than those without, and FPI- 6 scores were moderately positively correlated with dynamic OSI and dynamic MLSI under the eyes-closed condition. These results suggest that pronated foot posture could induce a change in postural stability, but not in knee isokinetic strength.

\section{INTRODUCTION}

The foot is a complex body structure with numerous rear, mid, and forefoot articulations and muscles. Forces produced and transmitted by the active structure (e.g. intrinsic and extrinsic foot muscles) and passive structure (e.g. plantar fascia) of the foot act across the foot joints, thus maintaining or changing foot posture [1], which has often called foot type in previous studies and can be classified into three types based on the rear foot position and medial longitudinal arch height: pronated, supinated, and neutral [2,3]. Although this classification places more emphasis on the functional aspect of the foot, the pronated foot and supinated foot are commonly associated with pes planus and pes cavus, respectively [4,5].

A pronated foot—or flat foot-has a low medial longitudinal arch height that causes overuse stresses in the muscles, tendons, and ligaments of the foot [6,7]. A pronated foot causes tibial internal rotation, which also affects the lower limb and the entire musculoskeletal system [8,9]. Several studies have reported that pronated foot has been linked to lower limb overuse injuries [9-11]: Tong and Kong [10] found pronated and supinated foot to be significantly associated with lower limb injuries, and Neal et al. [11] concluded that a pronated foot is a risk factor for medial tibial stress syndrome and patellofemoral 
pain, although the evidence was very limited. Therefore, classifying a pronated foot posture is essential in clinical practice to identify possible lower limb injury risk factors [12].

It is already well known that individuals with pronated foot have weakness in the ankle and foot musculature [1,7]. Foot posture not only affects the foot muscle strength but also the proximal muscle strength of the lower limb [9]. A recent study evaluated the size of the quadriceps muscles of individuals with pronated foot using ultrasound imaging and reported significantly smaller rectus femoris and vastus medialis oblique muscles than in neutral foot [13]. Therefore, it is necessary to identify the strength of knee joint muscle that might be affected by pronated foot.

The foot also plays an important role as a sensory structure in maintaining the body balance [14]. Even small changes in the foot, such as altered afferent feedback and muscle weakness, can also affect whole-postural stability $[15,16]$. Previous studies have reported that those with pronated foot have poorer postural stability than those with neutral foot $[6,15,17,18]$. In a study by Tsai et al. [17], pronated and supinated foot groups had poorer postural stability than neutral foot groups, however Hyong and Kang [19] reported no significant differences in the dynamic postural stability of different foot postures. This inconsistency may be due to the different task levels, as Tsai et al. [17] examined subjects in an eyes-closed condition, whereas Hyong and Kang [19] tested in an eyes-open condition. Therefore, we measured the postural stability in both eyes-open and eyes-closed conditions.

It is still unclear whether individuals with pronated foot have a greater mechanical disadvantage than those with neutral foot, especially for the postural stability and muscle strength of the knee joint. Thus, the purpose of this study was to identify whether a pronated foot posture influences knee isokinetic strength and static and dynamic postural stability. Formally, we hypothesized that individuals with a pronated foot posture have poorer knee isokinetic strength and static and dynamic postural stability. We also hypothesized that the grade of foot pronation deformity would be correlated with these parameters.

\section{MATERIALS AND METHODS}

\section{Subjects}

Forty-three healthy young male volunteers aged 18 to 26 years entered the study. The exclusion criteria were medicine taken within the last 24 hours, a history of musculoskeletal or neurological problems in the lower limbs within the previous 3 months, visual or vestibular problems, dizziness, and headache. Three volunteers were ruled out based on exclusion criteria and remaining forty subjects matched the criteria were included in this study (Figure 1). The subjects were divided into two groups according to their Foot Posture Index-6 (FPI6) scores: the neutral foot group (FPI-6 score: 0 to +5$)$ and the pronated foot group (FPI-6 score: +6 or more). None of the subjects had previous specific balance training (Table 1). This

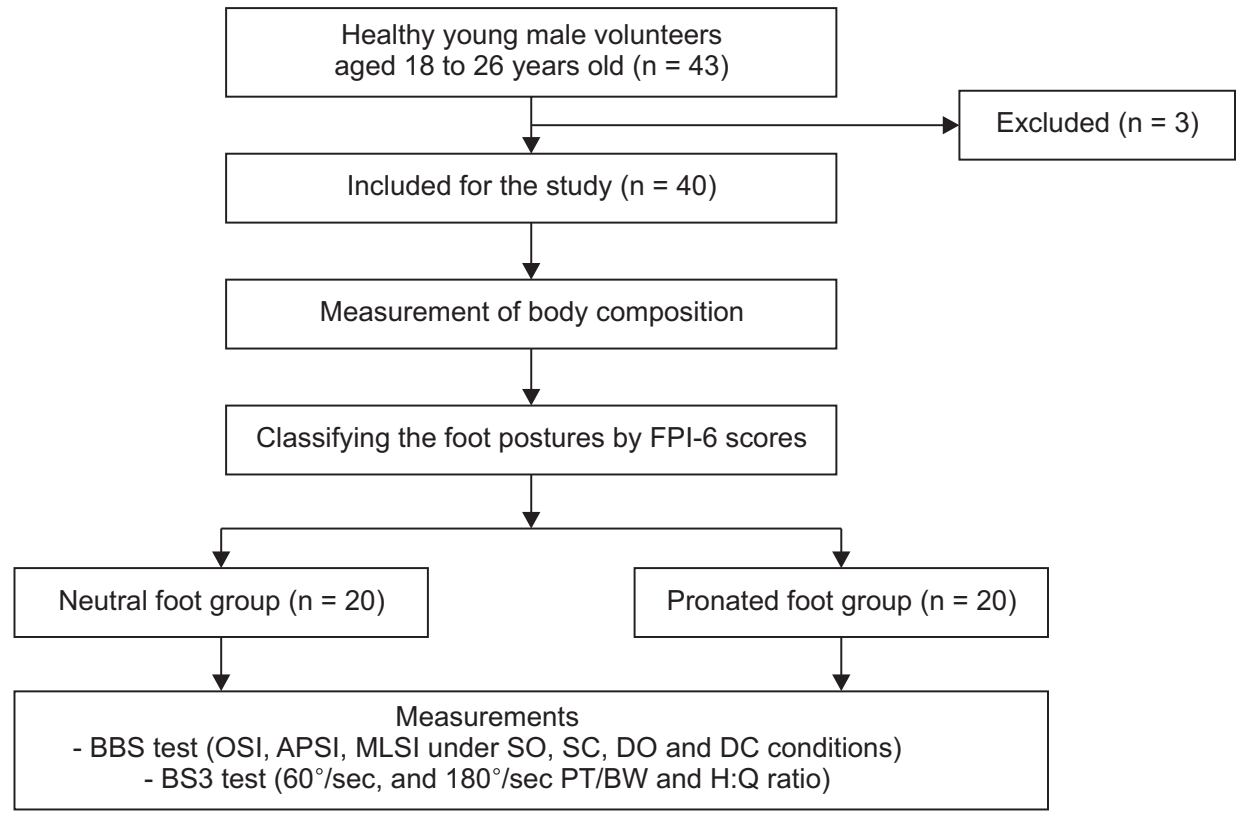

Figure 1. Experimental scheme of present study. Evaluation of foot posture by FPI-6 score, balance ability and knee isokinetic muscle strength. FPI-6, Foot Posture Index-6; BBS, Biodex Balance System; OSI, overall stability index; APSI, anteriorposterior stability index; MLSI, mediallateral stability index; SO, static under eyes-opened condition; SC, static under eyes-closed condition; DO, dynamic under eyes-opened condition; DC, dynamic under eyes-closed condition; BS3, Biodex Systems 3; PT/BW, peak torque/body weight; $\mathrm{H}: \mathrm{Q}$ ratio, hamstring to quadriceps ratio. 
Table 1. General characteristics of the subjects ( $N=40)$

\begin{tabular}{lcr}
\hline \multicolumn{1}{c}{ Group $(\mathrm{n})$} & Neutral $^{\mathrm{a}}(\mathrm{n}=20)$ & Pronated $^{\mathrm{b}}(\mathrm{n}=20)$ \\
\hline Age $(\mathrm{y})$ & $22.30 \pm 1.53$ & $21.85 \pm 2.25$ \\
Height $(\mathrm{cm})$ & $173.83 \pm 4.10$ & $172.19 \pm 6.26$ \\
Weight $(\mathrm{kg})$ & $81.41 \pm 13.80$ & $75.24 \pm 9.59$ \\
Body mass index $\left(\mathrm{kg} / \mathrm{m}^{2}\right)$ & $26.80 \pm 4.53$ & $25.36 \pm 2.90$ \\
Skeletal muscle mass $(\mathrm{kg})$ & $33.60 \pm 3.13$ & $32.64 \pm 3.60$ \\
Body fat $(\mathrm{kg})$ & $22.09 \pm 10.62$ & $17.66 \pm 5.63$ \\
Percent of body fat (\%) & $25.74 \pm 8.24$ & $23.13 \pm 5.17$ \\
Waist-hip ratio & $0.91 \pm 0.05$ & $0.89 \pm 0.04$ \\
FPl-6 score & $3.95 \pm 1.15$ & $7.50 \pm 1.15$ \\
Selected foot side (FPl-6 score) & Dominant foot: 30\% (6) & Dominant foot: $40 \%$ (8) \\
& Non-dominant foot: $70 \%$ (14) & Non-dominant foot: 60\% (12) \\
\hline
\end{tabular}

Values are presented as mean \pm standard deviation. FPI-6, Foot Posture Index -6 . ${ }^{a}$ The neutral foot group (FPI- 6 score 0 to +5$)$, ${ }^{b}$ the pronated foot group (FPI-6 score more than +6 ).

Table 2. The six assessment criteria of the FPI-6

\begin{tabular}{ll}
\hline \multicolumn{1}{c}{ Component } & \multicolumn{1}{c}{ Plane } \\
\hline Talar head palpation & Transverse \\
Curves above and below lateral malleoli & Frontal/transverse \\
Inversion/eversion of the calcaneus & Frontal \\
Bulge in the region of the talonavicular joint & Transverse \\
Congruence of the medial longitudinal arch & Sagittal \\
Abduction/adduction of the forefoot and & Transverse \\
the rear foot & \\
\hline
\end{tabular}

Data from the article of Redmond et al. (Clin Biomech 2006;21:89-98) [12].

study was approved by the Institutional Review Board of the College of Health and Welfare, Woosong University (approval No. 1041549-210413-SB-118), and all subjects were briefed on the study and provided written informed consent prior to participation.

\section{Instrumentation}

\section{1) InBody 120 Body Composition Analyzer}

Body composition factors of all subjects were measured by bioelectrical impedance assessment using an InBody 120 Body Composition Analyzer (InBody; Biospace Co. Ltd., Seoul, Korea). InBody analyzer, a simple, cost-effective device to measure body composition, has been found to have high intraclass correlation coefficients and small individual errors and can therefore be substituted for dual-energy $\mathrm{x}$-ray absorptiometry [20]. In this study, body weight $(\mathrm{kg})$, BMI $\left(\mathrm{kg} / \mathrm{m}^{2}\right)$, body fat mass $(\mathrm{kg})$, skeletal muscle mass $(\mathrm{kg})$, percent of body fat and waist-hip ratio were analyzed as the body composition factors.

\section{2) Foot Posture Index (FPI-6)}

Foot posture types were classified using the FPI-6, developed by Redmond [12], which incorporates six visual assessment
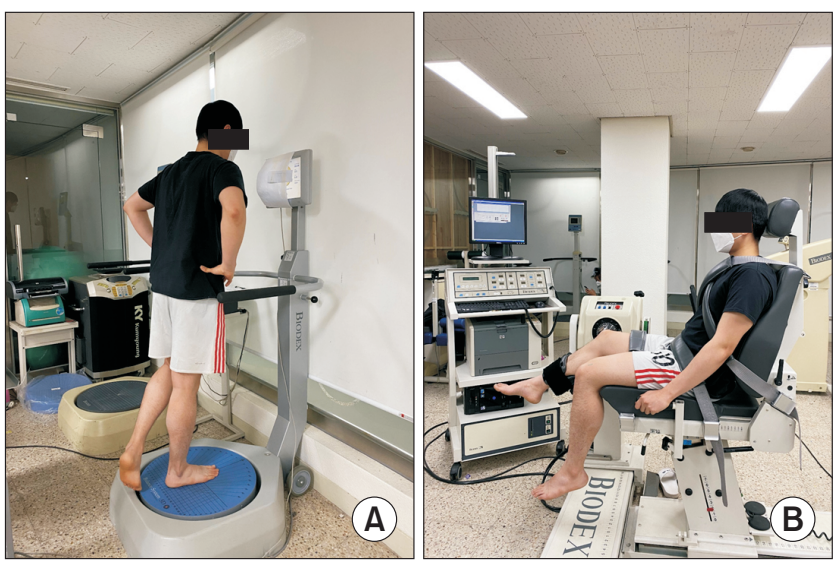

Figure 2. Instruments; (A) Biodex Balance System, (B) Biodex System 3 isokinetic dynamometer.

criteria (Table 2) without using other equipment for quantifying the degree of foot deformity. It measures foot posture in all three anatomical planes, while other classifying methods, such as the navicular drop test, footprint test, and medial longitudinal arch angle, usually provide uniplanar information [21]. The FPI-6 has been shown to have high validity and intra-rater reliability (intraclass correlation coefficient [ICC] $=0.893-0.958$ ) [22] and has also shown high inter-rater reliability (ICC $=0.85-$ 0.86) even among inexperienced clinicians [23]. Each criterion of the FPI-6 was scored using a 5-point Likert-type scale from -2 to +2 , and the foot posture types were classified by the total score: -12 to -5 (highly supinated), -4 to -1 (supinated), 0 to +5 (neutral), +6 to +9 (pronated), and +10 to +12 (highly pronated) [12].

\section{3) Biodex Balance System}

Static and dynamic postural stability were measured using a Biodex Balance System (BBS; Biodex Medical Systems Inc., 
Shirley, NY, USA) (Figure 2A). The BBS is a reliable multiaxial device for healthy individuals that can quantify, at one of 12 levels, a person's balance ability using a freely moving circular platform (most stable: level 12; most unstable: level 1) [24]. The BBS calculates three indices: overall stability index (OSI), anterior-posterior stability index (APSI), and medial-lateral stability index (MLSI); thus, a higher stability index score is representative of worse balance ability [25].

\section{4) Biodex Systems 3}

Isokinetic strength of the knee joint was measured using a Biodex System 3 (BS3; Biodex Medical Systems Inc., Shirley, NY, USA) isokinetic dynamometer (Figure 2B). Previous studies have reported high reliability of the BS3 in both clinical and research settings [26]. In this study, knee extensor and flexor peak torque/body weight (PT/BW) and hamstring to quadriceps $(\mathrm{H}: \mathrm{Q})$ ratios were measured.

\section{Procedures}

All experimental instrumentation were assessed by different researchers, respectively, and the measurements were blinded to each other. First, the general information data was recorded, then the body composition was measured at the beginning of the study procedures. To minimize errors, all subjects were dressed in T-shirts and instructed not to exercise or take meals for 2 hours before the measurements [27]. During the measurements, the subjects were not allowed to talk and were instructed to maintain the proper position: standing on the foot electrodes, arms spread about $30^{\circ}$ with straightened elbows, holding the hand electrodes, and looking straight forward $[27,28]$.

Foot posture of each subject was evaluated by FPI-6 score in a relaxed standing posture by same researcher. For the objectivity of assessment, the information of dominant side of the foot was blinded to the researcher of FPI- 6 while FPI- 6 measurements of both feet were taken. After the whole experimental procedures, the subjects were divided into neutral and pronated foot groups according to FPI- 6 score of one of the feet in the following manner: 1) FPI- 6 score of non-dominant foot was selected when FPI-6 scores were same on both feet to exclude the benefit by dominant foot. 2) The side of lower FPI-6 score was chosen when FPI-6 score of both feet were different. The procedure for FPI- 6 assessment described by Redmond [29] was followed in the current study (Table 2); the subjects stamped their foot several times and then stopped in a relaxed standing position with eyes looking straight ahead [18]. Each criterion of the FPI-6 was then assessed visually using palpations, and the total score was calculated.

To measure postural stability, each subject adopted a singleleg stance on the BBS platform in both static (locked platform) and dynamic (level 8) situations under eyes-open and eyesclosed conditions. Four different task levels of the BBS test were performed in order: static test with eyes open, static test with eyes closed, dynamic test with eyes open, and dynamic test with eyes closed (DC). The subjects were initially asked to place their supporting foot in an ideal center position [6]. For each test, the subjects performed three trials of a 20-second single-leg stance test on the platform while barefoot, with hands placed on iliac crests and with the unsupported leg placed behind the supported leg [25]. The BBS monitor was covered with paper during the test to eliminate bio-feedback effects. There was a 10-second break between the trials and a 1-minute break between each of the task levels. To avoid a learning effect, a 1-minute adaptation trial was provided before each task level [30].

The BS3 was used to measure PT/BW and H:Q ratios with three different angular velocities: $60 \% \mathrm{sec}$ (five reps), $90 \% \mathrm{sec}$ (five reps), and $180^{\circ} / \mathrm{sec}$ (five reps), in that order. There was a 20-second break between trials, and a practice trial was administered prior to the first trial at each angular velocity. In the BBS and BS3 tests, the dominant leg was tested first, followed by non-dominant leg by the same researchers. The subjects' FPI-6 scores were also blinded to the researchers handling the $\mathrm{BBS}$ and $\mathrm{BS3}$.

\section{Statistical Analysis}

Normal distribution of the data was assessed by Kolmogorov-Smirnov tests, with $\mathrm{p}>0.05$ indicating normality. To verify the differences in knee isokinetic strength and postural stability between the groups, the data were analyzed using independent t-tests. Pearson correlation coefficients were calculated to determine the relationship between FPI-6 scores and both knee isokinetic strength parameters and postural stability parameters. All data analyses were performed using IBM SPSS Statistics ver. 25 (IBM Corp., Armonk, NY, USA). The level of statistical significance was set at $\mathrm{p}<0.05$. 
Table 3. Comparison of postural stability between neutral foot and pronated foot group

\begin{tabular}{lcccc}
\hline & Neutral $(n=20)$ & Pronated $(n=20)$ & t-value & $p$-value \\
\hline SO OSI & $1.45 \pm 0.40$ & $1.60 \pm 0.50$ & -1.114 & 0.272 \\
SO APSI & $1.10 \pm 0.38$ & $1.29 \pm 0.52$ & -1.278 & 0.209 \\
SO MLSI & $0.67 \pm 0.31$ & $0.70 \pm 0.17$ & -0.385 & 0.703 \\
SC OSI & $2.78 \pm 0.77$ & $3.17 \pm 0.96$ & -1.423 & 0.163 \\
SC APSI & $1.99 \pm 0.61$ & $2.42 \pm 0.83$ & -1.894 & 0.066 \\
SC MLSI & $1.53 \pm 0.46$ & $1.61 \pm 0.46$ & -0.554 & 0.637 \\
DO OSI & $1.93 \pm 0.45$ & $1.82 \pm 0.58$ & -0.297 & 0.528 \\
DO APSI & $0.78 \pm 0.30$ & $0.81 \pm 0.34$ & 0.865 & 0.768 \\
DO MLSI & $1.60 \pm 0.48$ & $1.47 \pm 0.47$ & -1.658 & 0.392 \\
DC OSI & $3.34 \pm 0.68$ & $3.73 \pm 0.78$ & -0.444 & 0.106 \\
DC APSI & $1.73 \pm 0.51$ & $1.80 \pm 0.55$ & -2.382 & 0.659 \\
DC MLSI & $2.48 \pm 0.49$ & $2.87 \pm 0.55$ & $0.022^{*}$ \\
\hline
\end{tabular}

Values are presented as mean \pm standard deviation. SO, static under eyes-opened condition; SC, static under eyes-closed condition; DO, dynamic under eyes-opened condition; DC, dynamic under eyes-closed condition; OSI, overall stability index; APSI, anterior-posterior stability index; MLSI, medial-lateral stability index. *Significant at $p<0.05$.

Table 4. Comparison of knee isokinetic strength between neutral foot and pronated foot group ${ }^{\mathrm{a}, \mathrm{b}}$

\begin{tabular}{lcccc}
\hline & Neutral $(n=20)$ & Pronated $(n=20)$ & t-value & $p$-value \\
\hline $60^{\circ}$ Ex PT/BW & $236.85 \pm 38.93$ & $255.17 \pm 45.27$ & -1.372 & 0.178 \\
$60^{\circ} \mathrm{FxPT} / \mathrm{BW}$ & $122.88 \pm 28.74$ & $130.75 \pm 21.25$ & -0.985 & 0.331 \\
$90^{\circ} \mathrm{ExPT} / \mathrm{BW}$ & $212.87 \pm 41.37$ & $224.46 \pm 39.56$ & -0.906 & 0.371 \\
$90^{\circ} \mathrm{Fx} \mathrm{PT} / \mathrm{BW}$ & $115.41 \pm 28.33$ & $124.15 \pm 17.96$ & -1.165 & 0.251 \\
$180^{\circ} \mathrm{ExPT} / \mathrm{BW}$ & $155.19 \pm 16.81$ & $156.58 \pm 21.95$ & -0.162 & 0.872 \\
$180^{\circ} \mathrm{FxPT} / \mathrm{BW}$ & $87.99 \pm 21.70$ & $94.78 \pm 15.16$ & -1.147 & 0.259 \\
\hline
\end{tabular}

Values are presented as mean \pm standard deviation. Ex PT/BW, extension peak torque/body weight; Fx PT/BW, flexion peak torque/body weight. ${ }^{a}$ Results of independent $t$-test. ${ }^{b}$ Results of hamstring to quadriceps ratio are not shown.

\section{RESULTS}

The general characteristics including the rate of foot dominance in selected FPI-6 score (percentage of dominant and non-dominant foot) of each group are shown in Table 1; there were no significant differences in general characteristics between the groups nor in body composition factors. The FPI- 6 scores were $3.95 \pm 1.15$ in the neutral foot group and $7.50 \pm$ 1.15 in the pronated foot group (Table 1).

The static and dynamic postural stability indices are shown in Table 3. The DC MLSI was $2.48 \pm 0.49$ in the neutral foot group and $2.87 \pm 0.55$ in the pronated foot group. There was a significant difference between the groups in the DC MLSI ( $p$ $=0.022$ ) but not in the other stability indices; there were no significant differences in the PT/BW and H:Q ratios (Table 4).

The correlations between FPI-6 scores and the postural stability and knee isokinetic strength are shown in Table 5. FPI-6 scores were moderately positively correlated with DC OSI ( $\mathrm{R}=$ $0.344, p=0.030)$ and DC MLSI $(R=0.409, p=0.009)$, but there was no significant correlation between FPI- 6 scores and knee
Table 5. Pearson correlation coefficients between FPI-6 score and other parameters

\begin{tabular}{lll}
\hline & \multicolumn{2}{c}{ FPI-6 score } \\
\cline { 2 - 3 } Parameters & $\mathrm{R}$ & $\mathrm{p}$-value \\
\hline DC OSI & 0.344 & $0.030^{*}$ \\
DC APSI & 0.155 & 0.340 \\
DC MLSI & 0.409 & $0.009^{* *}$ \\
$60^{\circ} \mathrm{EXPT} / \mathrm{BW}$ & 0.076 & 0.641 \\
$60^{\circ} \mathrm{FX}$ PT/BW & 0.083 & 0.611 \\
$60^{\circ} \mathrm{H}$ :Q ratio & 0.047 & 0.772
\end{tabular}

Some results of postural stability and knee isokinetic strength are not shown. FPI-6, Foot Posture Index-6; DC, dynamic under closed eyes condition; OSI, overall stability index; APSI, anterior-posterior stability index; MLSI, medial-lateral stability index; Ex PT/BW, extension peak torque/ body weight; Fx PT/BW, flexion peak torque/body weight; $\mathrm{H}: \mathrm{Q}$ ratio, hamstring to quadriceps ratio. ${ }^{*} p<0.05,{ }^{* *} p<0.01$.

isokinetic strength.

\section{DISCUSSION}

The purpose of the current study was to determine whether pronated foot posture, as classified by the FPI-6, influences 
postural stability and knee isokinetic strength. No significant differences in general characteristics were found between the pronated and neutral foot groups (Table 1), and it is thus reasonable to assume that body composition did not affect the results. We found that individuals with pronated foot had a poorer dynamic MLSI under the eyes-closed condition ( $\mathrm{p}=$ 0.022 ) and that a higher FPI- 6 score was associated with the dynamic OSI $(R=0.344, p=0.030)$ and dynamic MLSI under the eyes-closed condition $(R=0.409, p=0.009)$, with no significant differences in the other stability indices or in knee isokinetic strength. Therefore, the results of the present study suggest that different foot postures affect some factors of postural stability, especially under dynamic stability in the eyesclosed condition.

\section{Foot Posture and Postural Stability}

The foot is an important sensory structure that provides $\mathrm{cu}^{-}$ taneous and muscular afferents when performing balance activities [14]. A pronated foot posture leads not only to mechanical changes, but also to somatosensory alterations [5], and may therefore affect static and dynamic postural stability. As with the results of previous studies $[6,15,17,18]$, the change of postural stability in pronated foot groups was also identified in present study. In particular, our study found the significant differences and correlations in some parameters of dynamic stability under eyes-closed condition. In contrast, some of studies have shown no changes in postural stability by foot posture [19], these various results between the previous studies seems to be due to difference of task level evaluating the postural stability. Postural balance is an integrated reaction that combines not only musculoskeletal functions, but also vision, vestibular sensory, somatic sensory and proprioception. Therefore, it might be explained that dynamic stability without visual information is the more adequate task difficulty for detecting a significant difference of postural stability according to foot posture.

Abdulwahab and Kachanathu [18] reported that, in the case of healthy young adults, a pronated foot does not affect static postural stability compared to neutral foot because the small movements of the center of gravity during static standing demand only a small effort from the foot. The static stability index under the eyes-open and eyes-closed conditions in the current study may therefore not show significant differences regardless of different foot postures. Koura et al. [6] also assumed that the level of difficulty in the dynamic balance test may affect their results; in their study, pronated and neutral foot groups were tested at two different BBS stability levels (levels 8 and 4), and a significant difference was found only at the relatively difficult stability level (level 4), which they concluded allows more foot displacement than the easier stability level at which no significant difference was found. Therefore, relatively easy BBS stability levels or task levels might be inappropriate for testing the postural stability of individuals with different foot postures because the foot displacement when maintaining balance may be inadequate. Alternatively, it might simply be that the tasks-static stability under the eyes-open and eyesclosed conditions and dynamic stability under the eyes-open condition-were too easy.

Additionally, according to Tables 3 and 5, no significant results were found in the dynamic APSI under the eyes-closed condition, and there may be a difference in postural stability between the anterior-posterior (AP) direction and the mediallateral (ML) direction. There are few previous studies that have examined postural stability separated into the AP and ML directions. Tsai et al. [17] reported greater maximum center of pressure (COP) displacement in the ML direction than the AP direction, and their study was supported by Kim et al. [31], who also stated that the foot structures in the AP direction are more stable than in the ML direction when maintaining balance. Based on these previous studies, we also confirmed that there is a significant change of dynamic MLSI, rather than dynamic APSI under the eyes-closed condition between groups. These results might indicate that postural stability in the AP direction is more stable than the ML direction under the eyesclosed condition in both groups.

\section{Foot Postures and Knee Isokinetic Strength}

Theoretically, pronation of the subtalar joint is coupled with an internally rotated tibia [9,32], so it is thought that an abnormal pronated foot may cause knee joint malalignment [33], which may cause weakness of the knee joint muscles due to the changes in the length-tension relationship and in proprioceptive information [13,34]. There is also preliminary evidence of smaller rectus femoris and vastus medialis muscles in individuals with pronated foot [13], but very few studies have investigated knee joint muscle strength in different foot postures.

However, we found no significant differences in knee isokinetic strength between the groups (Table 4) and no association between FPI-6 scores and knee isokinetic strength (Table 
5). One explanation for this result may be that the subjects were all healthy and did not have pathological pronated foot. The FPI-6 classification emphasizes functional aspects rather than pathological aspects $[4,5]$, and, in this study, the FPI-6 score of the pronated foot group was $7.50 \pm 1.15$, which was not in the excessively pronated foot range $(+10$ to +12$)$ and thus might not represent a sufficiently severe pathological condition to cause knee joint malalignment and muscle weakness. Future research should therefore investigate the classification criteria to clarify the differences between functional and pathological pronated foot. Another possible explanation for our results is that the level of physical performance between the groups may be different, although the subjects were healthy and there were no significant differences in body composition (Table 1). Kim et al. [35] concluded that total muscle mass in men was not an indicator of low performance levels, but that muscle strength was. In this study, the pronated foot group had a not significant, but a higher PT/BW ratio at all velocities than the neutral foot group (Table 4), and physical performance level might thus be lower in the neutral foot group. Further research is therefore recommended with a larger sample size and considering physical performance levels more intensively.

\section{Postural Stability and Knee Isokinetic Strength}

The proximal musculature in lower limb could have more influence on postural stability of both frontal (AP direction) and sagittal plane (ML direction) than distal musculature [36,37], therefore it is important to measure not only ankle musculature strength but also knee joint muscles. However, current study showed significant difference in only ML direction stability, but none in AP direction stability. In addition, there was no significance in knee isokinetic strength. These results indicate that other muscles control more in ML direction stability than knee joint muscles. In relation to anatomical factors, knee joint muscles usually work as AP direction stabilizers, and have no major specific stabilizers in ML direction [37]. In the study of Vahtrik et al. [38], total knee arthroplasty (TKA) group, both before and after TKA, showed greater COP displacement in AP direction but no significant difference in $\mathrm{ML}$ direction compared to healthy controls. Therefore, even though the subjects were not in pathological conditions, quadriceps and hamstring strength measurements might have limitation when discussing ML direction stability in current study. Rather, the gluteus muscles such as gluteus medius are more active when ML di- rection stability is challenged [39]. Thus, further research is recommended in hip joint muscle strength and ML direction stability.

We also recommend that the proportion of foot dominance should be carefully considered, although the foot dominance in selected FPI-6 score showed little differences in current study (Table 1). In previous studies [40-42], postural stability were not influenced by dominant side in healthy populations. However, to clarify correlation among FPI-6 score, postural stability and knee joint strength, later studies should consider foot dominance.

\section{CONCLUSIONS}

We demonstrated that individuals with pronated foot have poorer medial-lateral dynamic stability under an eyes-closed condition than those with neutral foot. FPI-6 scores for foot posture also showed moderate positive correlations with both dynamic OSI and dynamic MLSI under eyes-closed conditions, whereas there was no significant difference in knee isokinetic strength between the neutral and pronated foot groups and no association between FPI-6 scores and knee isokinetic strength. These results suggest that a pronated foot posture could induce a change in postural stability, but not in knee isokinetic strength. Even though knee isokinetic strength was not different between the groups, it might cause muscle strength problems potentially in those with pronated foot because an abnormal pronated foot might generate malalignment of the knee joint. Further research is therefore needed to determine the specific mechanism of pronated foot that changes postural stability and muscle balance and its influence on ankle and hip joints.

\section{CONFLICTS OF INTEREST}

No potential conflict of interest relevant to this article was reported.

\section{AUTHOR CONTRIBUTIONS}

Conceptualization: WC, HK, Sien P, JP, SS, Sookyoung P. Data curation: WC, HK, SIEN P, JP, SS, Sookyoung P. Formal analysis: WC, HK, JP, SS, Sookyoung P. Investigation: WC, HK, Sien P, JP, SS, Sookyoung P. Methodology: WC, HK, Sien 
P, JP, SS, Sookyoung P. Project administration: WC, HK, Sien P, JP, SS, Sookyoung P. Resources: WC, HK, Sien P, JP, SS, Sookyoung P. Software: WC, HK, SIEN P, JP, SS, Sookyoung P. Supervision: Sien P, Sookyoung P. Validation: WC, HK, Sien P, JP, SS, Sookyoung P. Visualization: WC, HK, Sien P, JP, SS, Sookyoung P. Writing - original draft: WC, HK, Sookyoung P. Writing - review \& editing: WC, Sookyoung P.

\section{ORCID}

Woochan Chun, https://orcid.org/0000-0002-5233-3187

Hee-su Kim, https://orcid.org/0000-0002-1684-5636

Sieun Park, https://orcid.org/0000-0001-5671-4799

Jihea Park, https://orcid.org/0000-0002-7148-1046

Seunghee Shim, https://orcid.org/0000-0001-8210-1347

\section{REFERENCES}

1. Angin S, Mickle KJ, Nester CJ. Contributions of foot muscles and plantar fascia morphology to foot posture. Gait Posture 2018;61:238-42.

2. Dahle LK, Mueller MJ, Delitto A, Diamond JE. Visual assessment of foot type and relationship of foot type to lower extremity injury. J Orthop Sports Phys Ther 1991;14(2):70-4.

3. Walker M, Fan HJ. Relationship between foot pressure pattern and foot type. Foot Ankle Int 1998;19(6):379-83.

4. Stovitz SD, Coetzee JC. Hyperpronation and foot pain: steps toward pain-free feet. Phys Sportsmed 2004;32(8):19-26.

5. Kodithuwakku Arachchige SNK, Chander H, Knight A. Flatfeet: biomechanical implications, assessment and management. Foot (Edinb) 2019;38:81-5.

6. Koura GM, Elimy DA, Hamada HA, Fawaz HE, Elgendy MH, Saab IM. Impact of foot pronation on postural stability: an observational study. J Back Musculoskelet Rehabil 2017;30(6): 1327-32.

7. Snook AG. The relationship between excessive pronation as measured by navicular drop and isokinetic strength of the ankle musculature. Foot Ankle Int 2001;22(3):234-40.

8. Tweed JL, Campbell JA, Avil SJ. Biomechanical risk factors in the development of medial tibial stress syndrome in distance runners. J Am Podiatr Med Assoc 2008;98(6):436-44.

9. Chuter VH, Janse de Jonge XA. Proximal and distal contributions to lower extremity injury: a review of the literature. Gait Posture 2012;36(1):7-15.
10. Tong JW, Kong PW. Association between foot type and lower extremity injuries: systematic literature review with metaanalysis. J Orthop Sports Phys Ther 2013;43(10):700-14.

11. Neal BS, Griffiths IB, Dowling GJ, Murley GS, Munteanu SE, Franettovich Smith MM, et al. Foot posture as a risk factor for lower limb overuse injury: a systematic review and metaanalysis. J Foot Ankle Res 2014;7(1):55.

12. Redmond AC, Crosbie J, Ouvrier RA. Development and validation of a novel rating system for scoring standing foot posture: the Foot Posture Index. Clin Biomech (Bristol, Avon) 2006;21(1):89-98.

13. Ashnagar Z, Hadian MR, Olyaei G, Talebian S, Rezasoltani A, Saeedi H, et al. Ultrasound evaluation of the quadriceps muscles in pronated foot posture. Foot (Edinb) 2019;38:86-90.

14. Viseux FJF. The sensory role of the sole of the foot: review and update on clinical perspectives. Neurophysiol Clin 2020; 50(1):55-68.

15. Cote KP, Brunet ME, Gansneder BM, Shultz SJ. Effects of pronated and supinated foot postures on static and dynamic postural stability. J Athl Train 2005;40(1):41-6.

16. Kim EK, Kim JS. The effects of short foot exercises and arch support insoles on improvement in the medial longitudinal arch and dynamic balance of flexible flatfoot patients. J Phys Ther Sci 2016;28(11):3136-9.

17. Tsai LC, Yu B, Mercer VS, Gross MT. Comparison of different structural foot types for measures of standing postural control. J Orthop Sports Phys Ther 2006;36(12):942-53.

18. Al Abdulwahab SS, Kachanathu SJ. The effect of various degrees of foot posture on standing balance in a healthy adult population. Somatosens Mot Res 2015;32(3):172-6.

19. Hyong IH, Kang JH. Comparison of dynamic balance ability in healthy university students according to foot shape. J Phys Ther Sci 2016;28(2):661-4.

20. McLester CN, Nickerson BS, Kliszczewicz BM, McLester JR. Reliability and agreement of various inbody body composition analyzers as compared to dual-energy X-ray absorptiometry in healthy men and women. J Clin Densitom 2020;23(3):44350.

21. Langley B, Cramp M, Morrison SC. Clinical measures of static foot posture do not agree. J Foot Ankle Res 2016;9:45.

22. Cornwall MW, McPoil TG, Lebec M, Vicenzino B, Wilson J. Reliability of the modified Foot Posture Index. J Am Podiatr Med Assoc 2008;98(1):7-13.

23. McLaughlin P, Vaughan B, Shanahan J, Martin J, Linger G. 
Inexperienced examiners and the Foot Posture Index: a reliability study. Man Ther 2016;26:238-40.

24. Oh KY, Kim SA, Lee SY, Lee YS. Comparison of manual balance and balance board tests in healthy adults. Ann Rehabil Med 2011;35(6):873-9.

25. Akhbari B, Salavati M, Mohammadi F, Safavi-Farokhi Z. Intraand inter-session reliability of static and dynamic postural control in participants with and without patellofemoral pain syndrome. Physiother Can 2015;67(3):248-53.

26. Van Driessche S, Van Roie E, Vanwanseele B, Delecluse C. Test-retest reliability of knee extensor rate of velocity and power development in older adults using the isotonic mode on a Biodex System 3 dynamometer. PLoS One 2018;13(5): e0196838.

27. Mikkola I, Jokelainen JJ, Timonen MJ, Härkönen PK, Saastamoinen E, Laakso MA, et al. Physical activity and body composition changes during military service. Med Sci Sports Exerc 2009;41(9):1735-42.

28. Lee SA, Kim AR, Yoo KT, Lee HS. Evaluation of muscle activity and foot pressure during gait, and isokinetic strength and balance in persons with functional ankle instability. J Korean Soc Phys Med 2018;13(3):27-37.

29. Redmond A. The foot posture index ${ }^{\odot}$ : easy quantification of standing foot posture. Six item version FPI-6. User guide and manual. University of Leeds [Internet]. Leeds: 2005 Aug [cited 2021 May 2]. Available from: https://pdfcoffee.com/footposture-index-pdf-free.html.

30. Karimi N, Ebrahimi I, Kahrizi S, Torkaman G. Evaluation of postural balance using the biodex balance system in subjects with and without low back pain. Pak J Med Sci 2008;24(3): 372-7.

31. Kim JA, Lim OB, Yi CH. Difference in static and dynamic stability between flexible flatfeet and neutral feet. Gait Posture 2015;41(2):546-50.

32. Tiberio D. The effect of excessive subtalar joint pronation on patellofemoral mechanics: a theoretical model. J Orthop
Sports Phys Ther 1987;9(4):160-5.

33. Gross KD, Felson DT, Niu J, Hunter DJ, Guermazi A, Roemer FW, et al. Association of flat feet with knee pain and cartilage damage in older adults. Arthritis Care Res (Hoboken) 2011; 63(7):937-44.

34. Solomonow M. Ligaments: a source of work-related musculoskeletal disorders. J Electromyogr Kinesiol 2004;14(1):49-60.

35. Kim YH, Kim KI, Paik NJ, Kim KW, Jang HC, Lim JY. Muscle strength: a better index of low physical performance than muscle mass in older adults. Geriatr Gerontol Int 2016;16(5): 577-85.

36. Gribble PA, Hertel J. Effect of lower-extremity muscle fatigue on postural control. Arch Phys Med Rehabil 2004;85(4):58992.

37. Bizid R, Margnes E, François Y, Jully JL, Gonzalez G, Dupui P, et al. Effects of knee and ankle muscle fatigue on postural control in the unipedal stance. Eur J Appl Physiol 2009;106(3): 375-80

38. Vahtrik D, Ereline J, Gapeyeva H, Pääsuke M. Postural stability in relation to anthropometric and functional characteristics in women with knee osteoarthritis following total knee arthroplasty. Arch Orthop Trauma Surg 2014;134(5):685-92.

39. Sims KJ, Richardson CA, Brauer SG. Investigation of hip abductor activation in subjects with clinical unilateral hip osteoarthritis. Ann Rheum Dis 2002;61(8):687-92.

40. Schorderet C, Hilfiker R, Allet L. The role of the dominant leg while assessing balance performance. A systematic review and meta-analysis. Gait Posture 2021;84:66-78.

41. Bigoni M, Turati M, Gandolla M, Augusti CA, Pedrocchi A, La Torre A, et al. Balance in young male soccer players: dominant versus non-dominant leg. Sport Sci Health 2017;13(2):253258.

42. Wikstrom EA, Tillman MD, Kline KJ, Borsa PA. Gender and limb differences in dynamic postural stability during landing. Clin J Sport Med 2006;16(4):311-5. 